\title{
MITIGATION OF WIND POWER FLUCUTATION IN MICRO-GRID SYSTEM DURING GRID AND ISLANDING MODE WITH BESS SCHEME
}

\begin{abstract}
This paper represents mitigation scheme of wind farm output power fluctuation in micro-grid system during grid and islanded mode. The impact of mitigation technique using sodium sulphur battery energy storage system is investigated during grid and islanded mode of micro-grid system. A micro-grid system with wind farm and photovoltaic system is used for the investigation of the mitigation of wind farm output power fluctuation using real wind speed data. In this paper, the control strategy of the inverter and dc-dc buck boost converter used in the battery energy storage system is presented with fixed and variable reference so that the wind farm power fluctuation can be extenuated. To verify the effectiveness of the control scheme, frequency analysis of the wind farm is investigated during the islanded mode. The micro-grid system modeling along with the mitigation control scheme is simulated in PSCAD/EMTDC.
\end{abstract}

\section{KEY WORDS}

Micro-grid, wind farm, power fluctuation, battery energy storage system and islanding mode.

\section{Introduction}

During this growing demand of electricity, Micro-grid system, a modern form of distributed generation with renewable energy resources has become popular in modern power system. A micro-grid is essentially what the name implies, a small-scale version of a larger utility grid. A micro-grid operates in two modes: grid mode and islanded mode. During grid mode, the micro-grid is connected to the utility grid. During islanded mode, the utility grid is disconnected from the micro-grid due to any intentional or unintentional disturbance occurred at the utility grid side. Small modular sources like wind, photovoltaic, fuel cells, batteries, electrolyzer, and diesel generators can be connected as the source of energy to form a micro-grid [1-3].

Wind power is considered to be one of the most promising renewable sources of energy; however, the generated electrical power has randomly varying and intermittent characteristics. The mitigation of wind power fluctuations has become one of the major issues of microgrid systems. Wind power fluctuation can be smoothened up to certain range by the blade pitch angle control of the wind turbine [4]. It is reported in [5, 6] that superconducting magnetic energy storage (SMES) system can be used to smoothen the wind power fluctuation. A flywheel energy system is proposed in [7, 8]. Energy capacitor system (ECS) composed of power electronic devices and electric double layer capacitors (EDLC) has been proposed for smoothing the wind power fluctuation in [9-11]. A battery energy storage system (BESS) [12] has been reported to smooth the power fluctuation. Also, if BESS is integrated with STATCOM, then this integration technique can provide both real and reactive power quite well [13]. However, wind power smoothing challenges in micro-grid system, both in grid connected and islanding modes, have not been investigated in details.

An overview of the different storage technologies, their applications, and limitations are discussed in [14-18]. The earlier reviews on storage technology $[14,15]$ focus exclusively on lead-acid battery technology. In [14] the economic models, their controls, ratings and applications found in US power systems are discussed and in [15] the possible future applications are suggested. In [15] the use of battery energy technology to improve the power quality and reliability of the power system are discussed. Some of the reviews carried out in $[16,17]$ discuss about the various storage technologies and suggest that so far the battery technology is the most widely used storage device for power system applications.

Lots of commercial companies are manufacturing sodium sulfur battery due to its unique characteristics. In mid 1980s TEPCO/NGK commenced joint R\&D for NAS. In April 2002, over 50 demo projects were initiated and NAS system was offered commercially in Japan, by TEPCO and NGK teaming with Toshiba plus other PCS vendors. 40MW NAS was produced in 2003 and 65MW was produced in 2004 by NGK. In July 2004, 9.6MW/57.6 MWh project by TEPCO for Hitachi's auto system factory was initiated. Sodium sulfur (NAS) battery is an advanced secondary battery developed by Tokyo Electric Power Company (TEPCO) and NGK Insulators, Ltd. since 1983 [19]. It is reported in [19] that NAS battery is the most suitable one for use in large scale battery energy storage system due to its long life cycle and outstanding efficiency.

In micro-grid system operating in islanding mode, frequency fluctuation is an important issue which needs to be considered according to the grid codes. Different operating frequency limits are imposed in various grid codes [20]. According to [20], upon reaching a frequency at the grid connection point of less than $46.5 \mathrm{~Hz}$ or greater than $53.5 \mathrm{~Hz}$, offshore wind farms must disconnect from the grid with a time delay of $300 \mathrm{~ms}$. Frequency operating limit of Irish grid code and Danish grid code is between $47 \sim 52 \mathrm{~Hz}$ and $47 \sim 51.5 \mathrm{~Hz}$ [20]. In this paper, mitigation of wind farm output power fluctuation in a hybrid ac-dc based micro-grid system during grid mode and islanding 


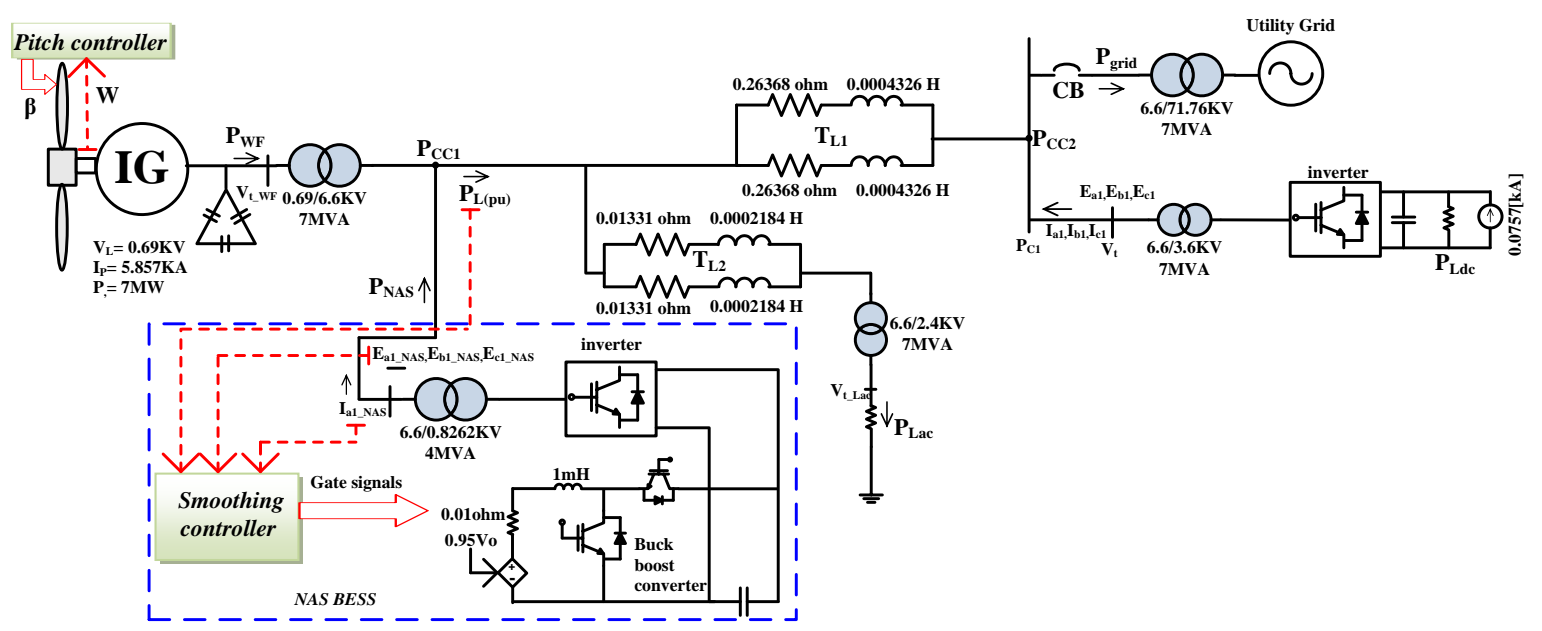

Fig.1 Proposed Model System

mode is investigated using sodium sulfur battery energy storage system due to its efficient characteristics. It is shown in this paper that during the islanding operation of micro-grid system, the power fluctuation mitigation operation of sodium sulfur battery energy storage system improves the frequency variations and mitigates the power fluctuation of wind farm during both modes leading to a stable grid and islanding operation of the micro-grid system which fulfils the grid code for frequency operating limit of UK, Ireland and Denmark [20]. In section 2, the model system is shown. Dynamic system modeling is shown in brief in section 3. The control strategy and simulation results are shown in section 4 and 5 respectively. Finally the conclusion is shown in section 6 .

\section{Proposed Model System}

A hybrid micro-grid system is used in this paper which is extracted from the benchmark system of the IEEE standard 399-1997 [21], with some modifications to allow the grid and islanded operation of micro-grid as shown in figure 1. A wind farm of 7MW and a photovoltaic system of $0.5 \mathrm{MW}$ is used in the model. Ac and dc loads are used. The sodium sulfur battery energy storage system along with inverter and dc-dc buck-boost converter is shown in the figure with dotted block.

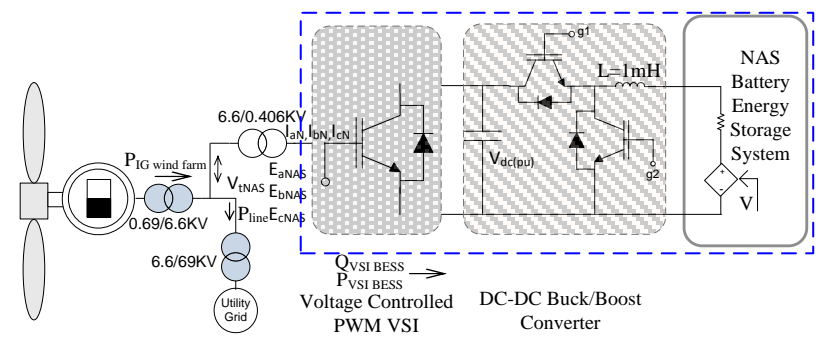

Fig.2 Schematic diagram of Integrated NAS BESS
The parameters of the proposed micro-grid system and the parameters of the induction generators used are given in the Table 2.1 and Table 2.2 respectively in Appendix. The NAS battery energy storage system (NAS BESS) integrated at the common terminal of the induction generators is rated at $4 \mathrm{MW}$. Details of the smoothing operation by NAS BESS are discussed in later sections. Figure 2 depicts the schematic diagram of integrated sodium sulfur battery energy storage system (NAS BESS). The battery energy storage system is connected at the terminal point of the wind farm. The sodium sulfur battery energy storage system consists of voltage controlled pulse width modulation voltage source inverter and dc-dc buck-boost converter along with the equivalent model of sodium sulfur battery. The voltage controlled pulse width modulation voltage source inverter (PWM VSI) is used to control the dc link voltage of the VSI and terminal voltage $\left(\mathrm{V}_{\mathrm{tNAS}}\right)$ at the point of common coupling between the wind farm and the NAS BESS. The dc-dc buck-boost converter is used to control the fluctuated wind farm output power $\mathrm{P}_{\mathrm{IG}}$ wind farm. The whole system leads to the smoothing of the fluctuated wind farm output power. $\mathrm{P}_{\text {line }}$ indicates the smooth power. Details control scheme of the voltage source inverter and the dc-dc buckboost converter is shown in the following subsections.

\section{Dynamic System Modeling}

\subsection{Modeling of wind turbine}

Turbines capture kinetic energy from the wind and convert it into electrical energy. The wind turbine output torque and extracted power can be expressed by the following equations $[22,23]$ :

$$
P_{m}=\frac{1}{2} \cdot \rho C_{P}(\lambda, \beta) A V_{W}{ }^{3}[W]
$$


Where

$\mathrm{Pm}$ is the power,

$\rho$ is the air density $[\mathrm{kg} / \mathrm{m} 3]$,

$\mathrm{R}$ is the radius of the blade [m],

$\mathrm{VW}$ is the wind speed $[\mathrm{m} / \mathrm{s}]$,

A is the cross sectional area of the turbine [m2].

$\mathrm{CP}(\lambda, \beta)$ is the power coefficient given by

$C_{P}(\lambda, \beta)=\frac{1}{2} \cdot\left(\Gamma-0.02 \beta^{2}-5.6\right) e^{-0.17 \Gamma}$

Where, $\quad \Gamma=\frac{R(3600)}{\lambda(1609)}$ and $\lambda=\frac{\omega_{m} R}{V_{w}}$ is the tip speed ratio.

$\omega \mathrm{m}$ represents the rotor mechanical speed and $\beta$ is the pitch of the rotor blades. The power coefficient $\mathrm{CP}$ is a measure how much of energy in the wind is extracted by the turbine. The power coefficient $\mathrm{CP}$ is a function of the tip speed ratio $(\lambda)$ and the pitch angle $(\beta)$. Pitch control allows limiting of the turbine speed at high wind speeds.

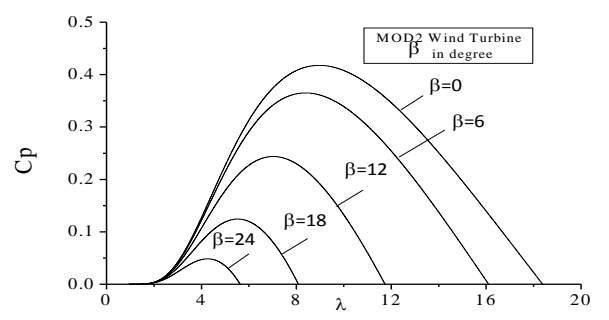

Fig. $3 \mathrm{CP}-\lambda$ curves for different pitch angles Figure 3 shows the $\mathrm{CP}-\lambda$ curves for different pitch angles of fixed speed wind turbine (FSWT).

\subsection{Modeling of pitch controller}

Figure 4 shows the modeling of pitch controller for fixed speed wind turbine [24]. The pitch angle of the blades is controlled to optimize the power extraction of wind turbine as well as to prevent overrated power production in strong wind. When wind speed is higher than rated value, the power limitation active by adjusting the pitch angle using the pitch-control which is shown in the Figure. $\mathrm{P} \_\mathrm{IG}$ is the power generated from the induction generator. The error between the P_IG and reference power 1 is taken as input to the PI controller. The PI controller output is connected to the limiter and then it is connected to rate limiter and pitch angle is generated.

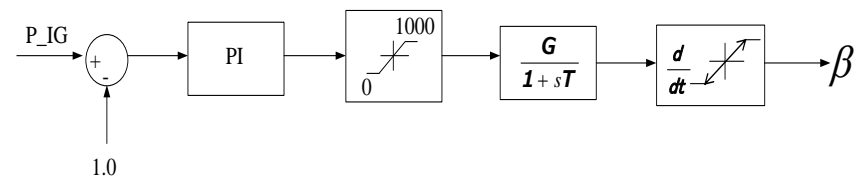

Fig.4 Pitch controller for fixed speed wind turbine

\subsection{Modeling of sodium sulfur battery energy storage system}

Figure 5 shows the characteristics curve of sodium sulfur battery energy storage system. Graph of inside of battery remaining capacity battery (EC) against internal force (V0) is shown in the Figure. When battery is fully charged, the battery internal force is V0. E indicates the depth of discharge of the NAS battery energy storage system in MJ [19]. EC indicates the remaining capacity of the battery in MJ. The total capacity of the sodium sulphur battery energy storage system is 4MW/2.857MWh.

From the characteristics curve, the sodium sulfur battery internal force can be described by the following equation.

$$
V=\frac{-\mathrm{V}_{0} \times E}{72000}+\mathrm{V}_{0}
$$

Where, $\mathrm{E}$ is the depth of discharge. For the modeling of the NAS BESS, the battery is considered to be $65 \%$ charged initially. As the total charge capacity of the battery is $10285.7 \mathrm{MJ}$. Considering $35 \%$ depth of discharge initially, the depth of discharge of $\mathrm{E}$ becomes $3600 \mathrm{MJ}$. Considering the value of $\mathrm{E}$ at equation 3, the resulting internal battery voltage is equal to:

$V=0.95 \times V_{0}$

The battery power is modeled with a capacity of $4 \mathrm{MW}$. Initial value of battery internal force is $0.95 \mathrm{~V} 0.5 \%$ voltage drop across the internal resistance is considered. It is assumed that the battery resistance is constant. The power across the battery is shown in the following equation.

$$
\begin{aligned}
& P_{N A S}=\left(0.95 \times V_{0}-I R_{N A S}\right) \times I \\
& I R_{N A S}=0.95 \times V_{0} \times 0.05
\end{aligned}
$$

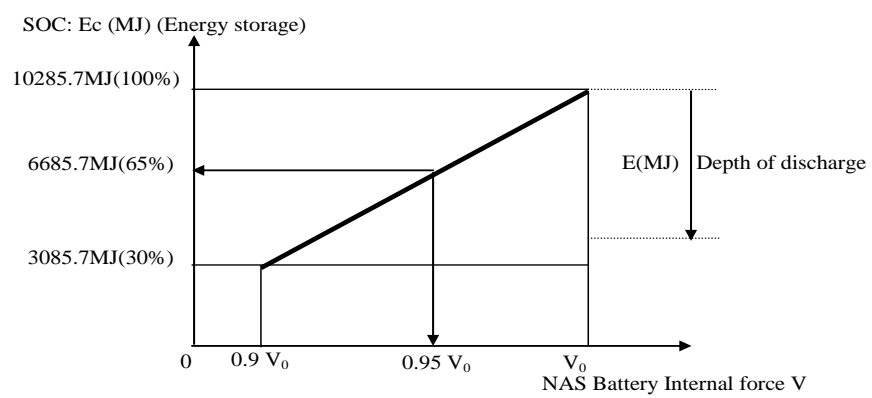

Fig.5 Characteristics curve of NAS battery, Battery internal force against (V) the inside of the battery remaining capacity $(\mathrm{EC})$

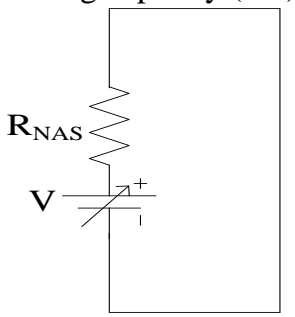

Fig.6 Sodium sulfur (NAS) battery model 
Where, PNAS and RNAS indicate the power capacity and internal resistance of the battery respectively and I indicates the current through the battery. Thus the model of NAS battery is represented in Figure 6, where the calculated internal resistance from equation 5 is 0.0026485874 ohm.

\section{Control Strategy}

\subsection{Inverter control}

Figure 7 shows the control block diagram of voltage controlled pulse width modulation voltage source inverter of sodium sulphur battery energy storage system as shown in figure 2. PI controllers are used to control the terminal voltage $\mathrm{V}_{\text {tNAS }}$ and dc link voltage $\mathrm{V}_{\mathrm{dc}(\mathrm{pu})}$. PLL provides the angle $\theta_{1}$ for the abc-to-dq0 and dq0-to-abc transformation. The currents $I_{a N}, I_{b N}$ and $I_{c N}$ are sampled from $0.406 \mathrm{kV}$ side of transformer as shown in Figure 2. The d-axis current controls the dc link voltage while the q-axis current controls the reactive power of the inverter.
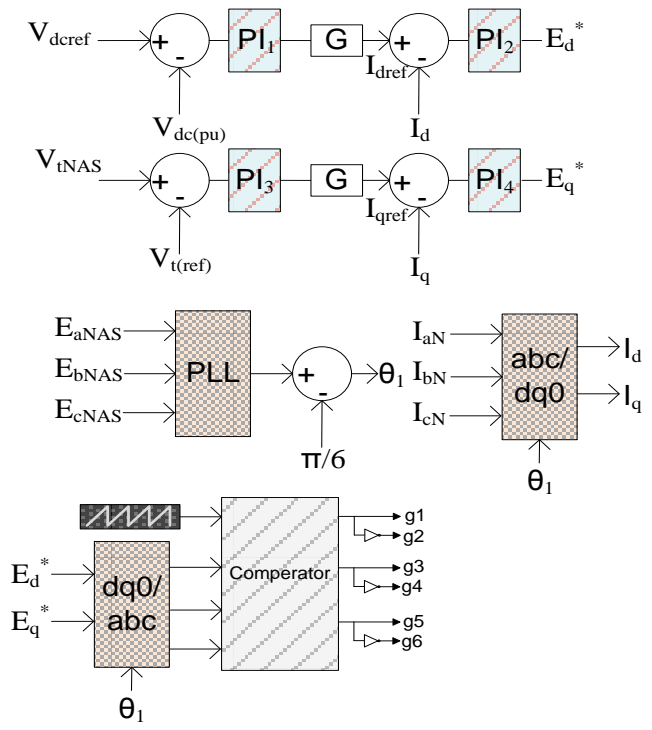

Fig.7 Control scheme of the voltage controlled PWM voltage source inverter

\subsection{Buck boost converter}

The control strategy of the dc-dc buck boost converter used in BESS power flow control is shown in Figure 8. The PWM carrier frequency is $450 \mathrm{~Hz}$. The error signal between the line power Pline (after the point of wind turbine generator and BESS connection) and reference (smooth) power is fed to the PI controller. Then output of the PI controller is compared with the carrier frequency and thus the gate signals are generated for the buck-boost converter. Using the controller, power Pline is forced to track its reference Pref.

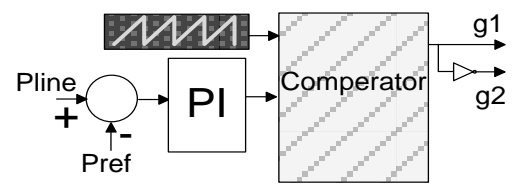

Fig.8 Control block of the dc-dc buck/boost converter

\subsubsection{Mitigation of power using constant reference}

The power smoothing of wind farm fluctuated output power can be performed by a constant reference. This translates to a constant Pref in the control scheme of Figure 8.

\subsubsection{Mitigation of power using variable reference}

For variable power smoothing operation, variable reference is used in $\mathrm{P}_{\text {ref }}$ as shown in fig. 8. Simple low pass filter of wind farm fluctuated output power is used as variable reference for the variable power smoothing operation. The time constant of the low pass filter is $10 \mathrm{~s}$. The benefit of using a variable reference rather than a constant reference is less charging and discharging of battery. In case of constant reference, the battery has to charge or discharge high. But in variable reference, as the reference varies along with the fluctuated wind output power, the charging and discharging of battery is comparatively low.

\section{Simulation Results}

To verify the effectiveness of the power smoothing operation, simulation analysis has been performed in PSCAD/EMTDC [25]. Real wind speed data measured in Hokkaido Island, Japan shown in Figure 9 is used to drive the wind farm. The time step and simulation time has been chosen to be $20,000 \mu \mathrm{s}$ and $300 \mathrm{~s}$, respectively. Aggregated wind farm of 7MW and 0.5 MW photovoltaic output power are considered. The simulation responses of the power smoothing operation by using constant reference and variable reference are shown in following subsections.

\subsection{Mitigation of wind power fluctuation during grid mode}

\subsubsection{Mitigation of power using constant reference}

Sodium sulfur battery energy storage system (NAS BESS) of $4 \mathrm{MW}$ rating is integrated at the wind farm end to smooth the fluctuating output power to a constant 5MW. Batteries below 4MW rating has been tested in simulation and it is seen that batteries lesser than $4 \mathrm{MW}$ is not able to smooth the fluctuated wind output power. 


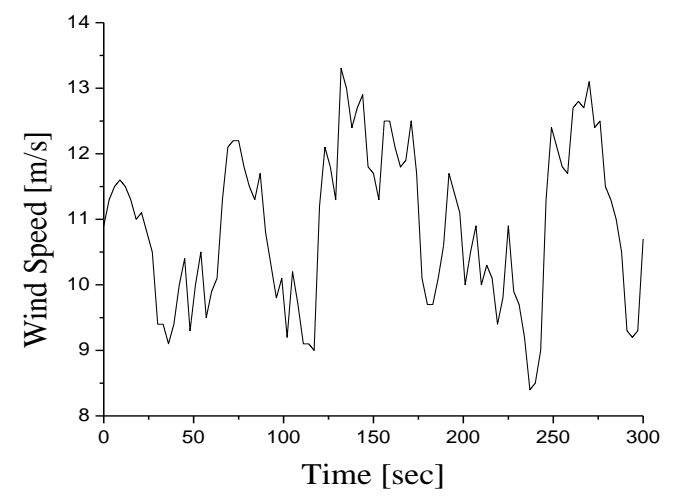

Fig.9 Real Wind speed

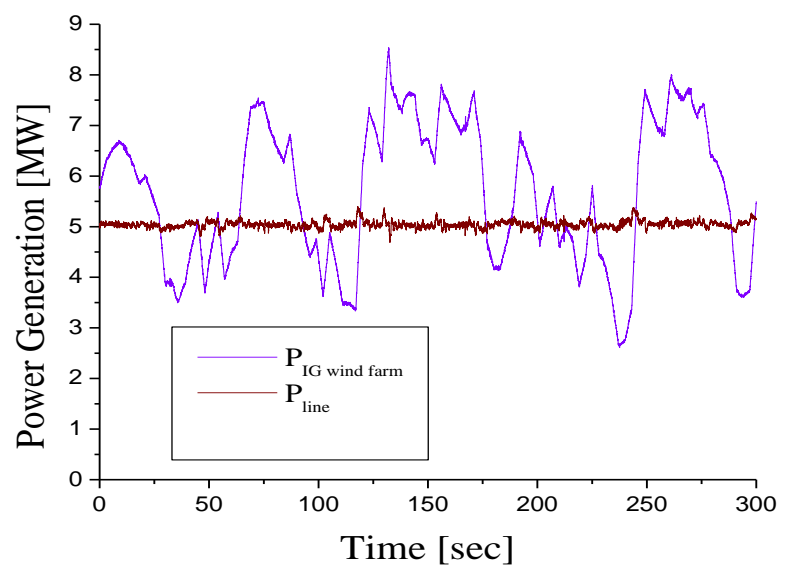

Fig.10 Wind farm output and smoothen power using constant reference

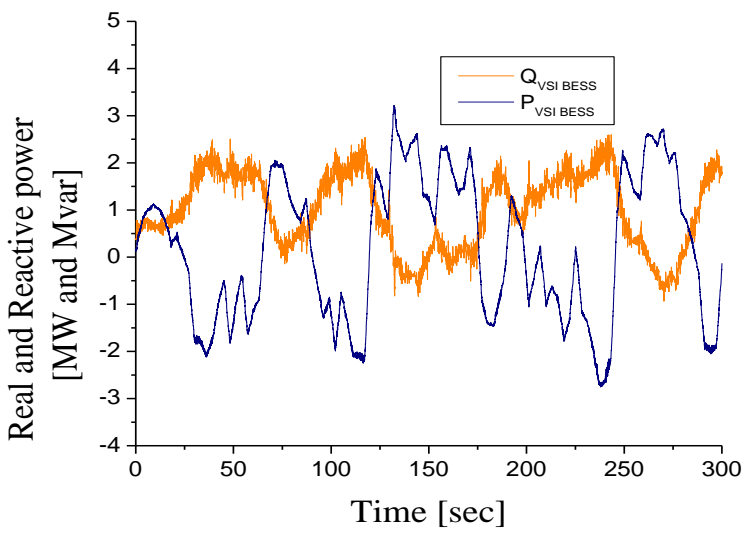

Fig.11 Real and reactive power of VSI with BESS with constant reference

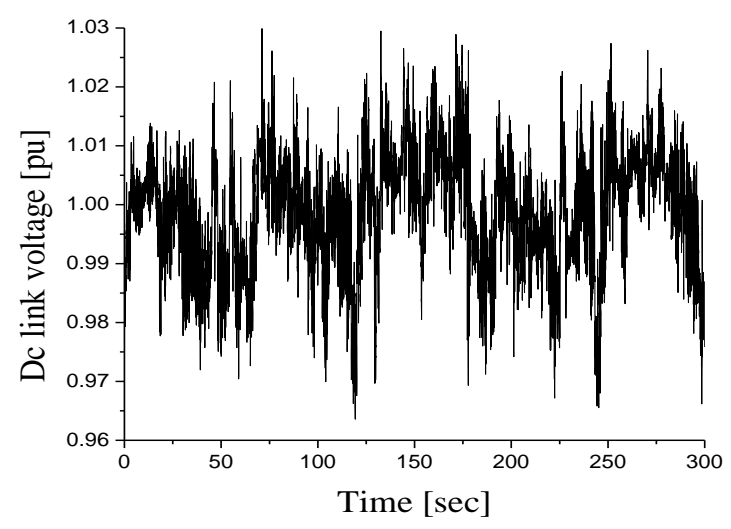

Fig.12 Dc link voltage of BESS with constant reference of NAS BESS

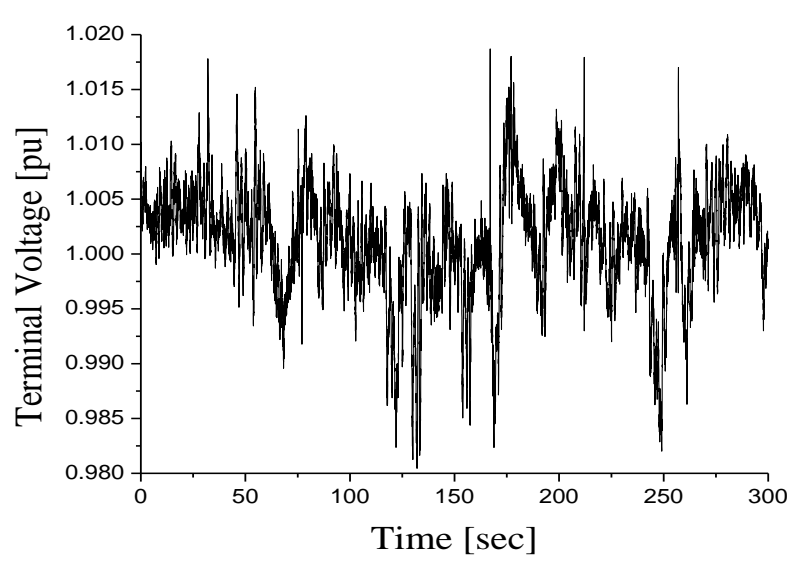

Fig.13 Terminal voltage at PCC of NAS and wind farm using constant reference

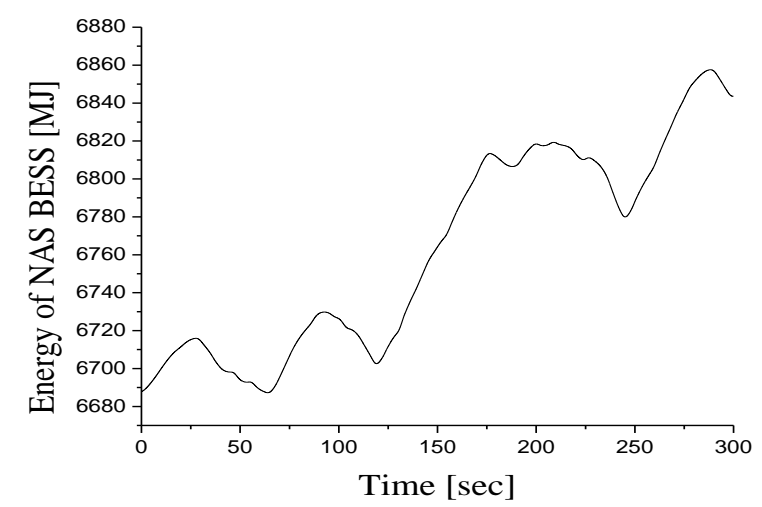

Fig.14 Energy level of NAS battery using constant reference 
Responses of the fluctuating output power of wind farm, along with the smooth line power, real power and reactive power provided by the voltage source inverter with NAS battery ESS are shown in Figures 10 and 11 respectively. The blue color trace in Figure 10 shows the fluctuating wind farm power output $\mathrm{P}_{\mathrm{IG}}$ wind farm and almost straight line in brown color shows the smooth wind farm output $\mathrm{P}_{\text {line }}$ at 5MW. DC link voltage of NAS BESS inverter is shown in Figure 12. Terminal voltage at PCC of NAS BESS and grid side is shown in Figure 13. Stored energy in the NAS BESS is shown in Figure 14. These responses show the effectiveness of the battery model in terms of smoothing the fluctuating output power of the aggregated wind farm.

\subsubsection{Mitigation of power using variable reference}

Variable reference is used in the control scheme of dc-dc buck-boost converter. Responses of the fluctuating output power of wind farm, along with the smooth line power, real power and reactive power provided by the voltage source inverter with NAS battery ESS are shown in Figures 15 and 16 respectively. The blue color trace in Figure 15 shows the fluctuating wind farm power output and line in brown color shows the smooth wind farm output $\mathrm{P}_{\text {line }}$ following variable reference. DC link voltage of NAS BESS inverter is shown in Figure 17. Terminal voltage at PCC of NAS BESS and wind farm is shown in Figure 18. Stored energy in the NAS BESS is shown in Figure 19. These responses show the effectiveness of the battery model in terms of smoothing the fluctuating output power of the aggregated wind farm.

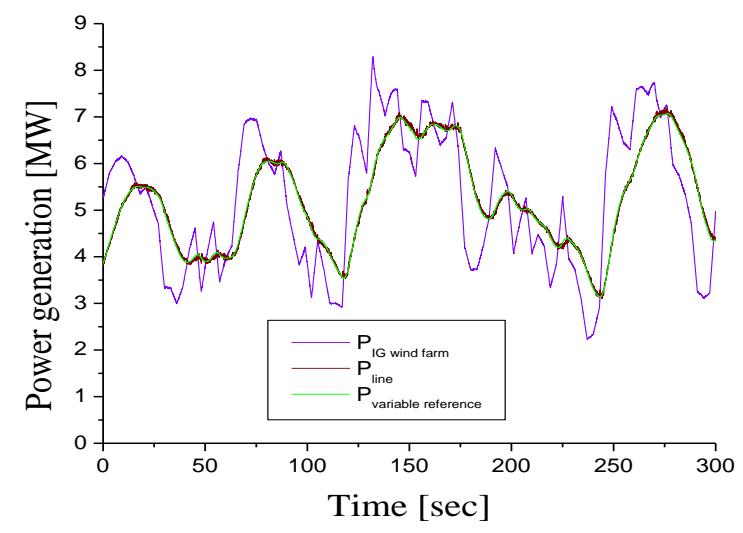

Fig.15 Wind farm output and smoothen power using variable reference

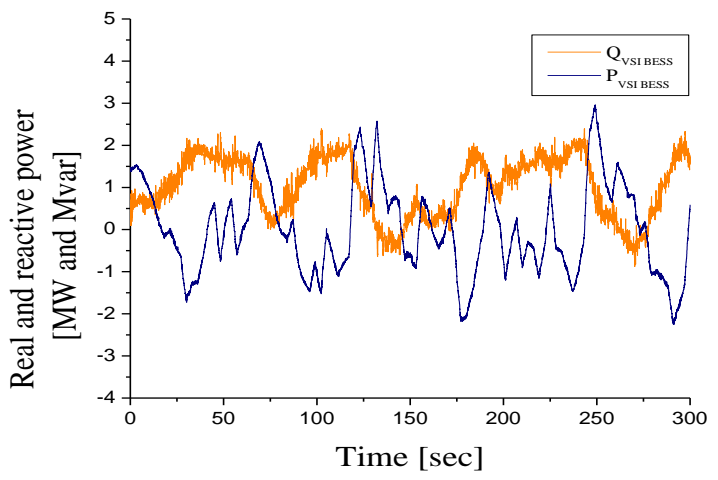

Fig.16 Real and reactive power of VSI with BESS with variable reference

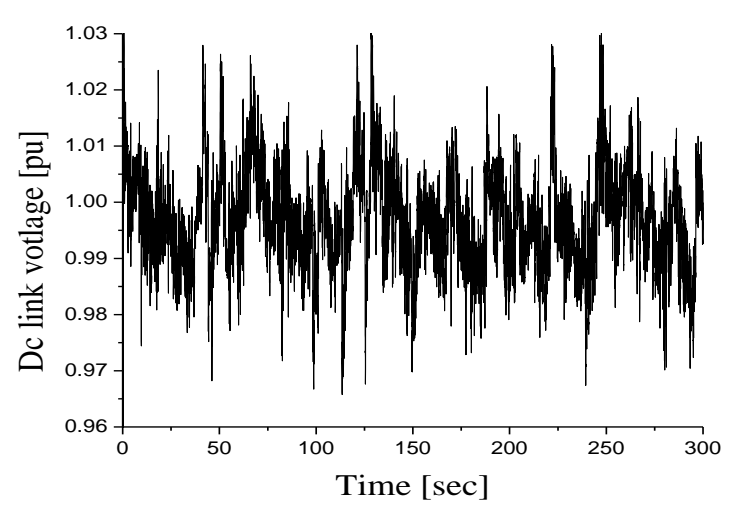

Fig.17 Dc link voltage of BESS with variable reference of NAS BESS

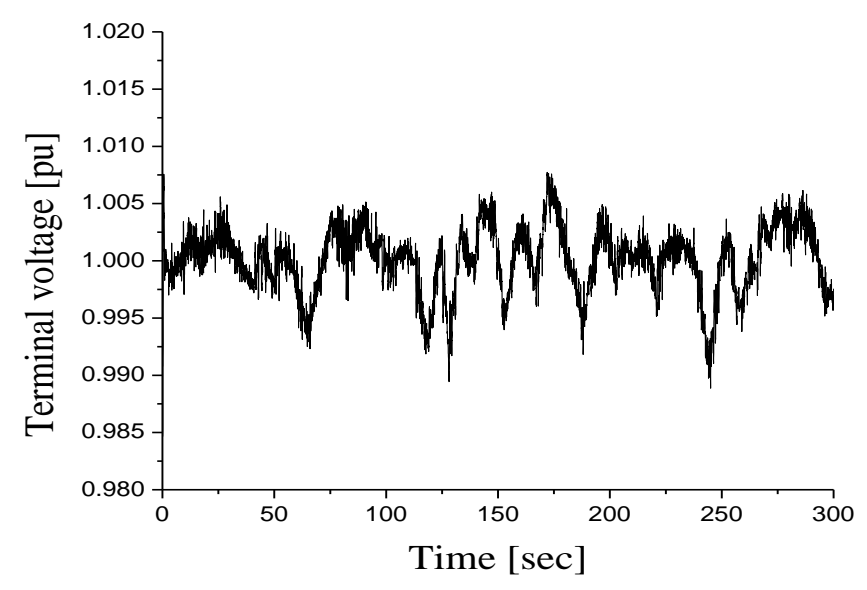

Fig.18 Terminal voltage at PCC of NAS and wind farm using variable reference 


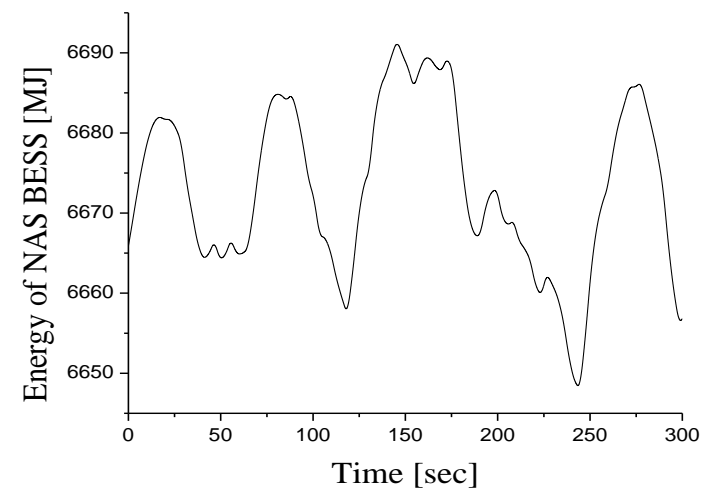

Fig.19 Energy level of NAS battery using variable reference

\subsection{Mitigation of wind power fluctuation and frequency analysis during islanding mode}

Figure 20 depicts the islanding and grid resynchronization mode of micro-grid system. In figure 20 (a) and (b), the fluctuated wind farm output power, smoothing power and grid power is shown respectively for smoothing and without smoothing operations. Figure 20 (c) depicts the wind farm frequency for smoothing and without smoothing operation. It is clearly observed in the response that frequency of the wind farm in the micro-grid does not operate within the acceptable range during islanding mode when proposed energy storage device for fluctuation mitigation is not used in the system. When mitigation is enabled by the energy storage system, the frequency of wind farm stays within the operating limit during islanding mode which fulfils the Irish and Danish grid code [20].

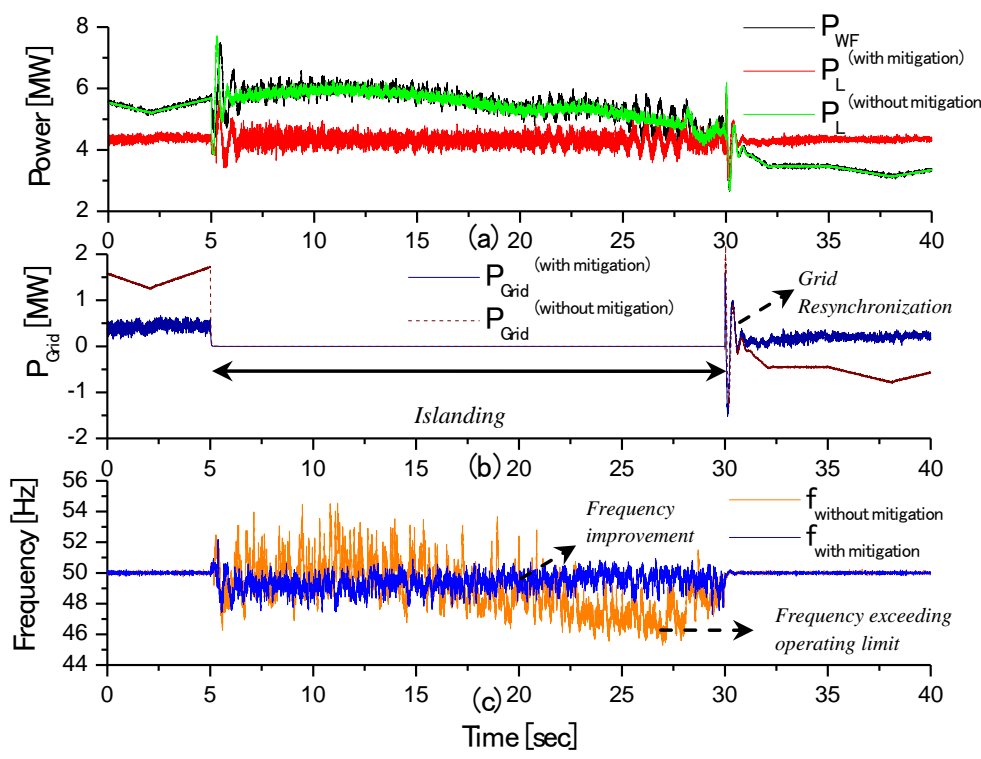

Fig.20 Impact of smoothing on frequency during islanding mode

\section{Conclusion}

The hybrid micro-grid system with mitigation technique of sodium sulphur battery energy storage system is presented in this paper with detail modeling. The effectiveness of the control strategy is verified in PSCAD/EMTDC. The mitigation technique during grid mode with fixed and variable reference is shown in details. From the simulation results, it is found that the battery charging and discharging is low when variable reference is used which will help to avoid overcharging or depletion of battery below the threshold level. Frequency analysis of wind farm with mitigation and without mitigation is presented in the paper for islanding mode. The results shown that during the islanding mode, the frequency of the wind farm crosses the operating limits without mitigation technique. On the other hand, with the mitigation of the sodium sulpher battery energy storage system, the frequency stays within the operation range during islanded mode fulfilling grid code. It can be concluded from this paper that the proposed mitigation technique of wind power fluctuation leads the micro-grid system to an improved and well dynamic system during and subsequent to the islanding mode.

\section{Acknowledgement(s)}

The authors would like to would like to acknowledge the contributions from Kitami Institute of Technology for providing real wind speed data.

\section{Appendix}

Table 1

Micro-grid parameters

\begin{tabular}{|l|l|}
\hline \multicolumn{1}{|c|}{ Parameters } & \multicolumn{1}{c|}{ Value } \\
\hline Base MVA of converter & $7 \mathrm{MVA}$ \\
\hline Base voltage of converter & $3.6 \mathrm{kV} \mathrm{V} \mathrm{V}_{\mathrm{LL}}$ \\
\hline Base current of converter & $1.1226 \mathrm{~A}$ \\
\hline Resistance $\left(\mathrm{T}_{\mathrm{L} 1}, \mathrm{~T}_{\mathrm{L} 3}\right.$ and $\left.\mathrm{T}_{\mathrm{L} 4}\right)$ & $0.26368 \Omega$ \\
\hline Inductance $\left(\mathrm{T}_{\mathrm{L} 1}, \mathrm{~T}_{\mathrm{L} 3}\right.$ and $\left.\mathrm{T}_{\mathrm{L} 4}\right)$ & $0.0004326 \mathrm{H}$ \\
\hline Length $\left(\mathrm{T}_{\mathrm{L} 1}, \mathrm{~T}_{\mathrm{L} 3}\right.$ and $\left.\mathrm{T}_{\mathrm{L} 4}\right)$ & $2.06 \mathrm{~km}$ \\
\hline Resistance $\left(\mathrm{T}_{\mathrm{L} 2}\right)$ & $0.013312 \Omega$ \\
\hline Inductance $\left(\mathrm{T}_{\mathrm{L} 2}\right)$ & $0.00002184 \mathrm{H}$ \\
\hline Length $\left(\mathrm{T}_{\mathrm{L} 2}\right)$ & $104 \mathrm{~m}$ \\
\hline Total AC generation & $7 \mathrm{MW}$ \\
\hline Total DC generation & $0.5 \mathrm{MW}$ \\
\hline AC loads & $\mathrm{Up} \mathrm{to} 2.5 \mathrm{MW}$ \\
\hline DC loads & $\mathrm{Up}$ to $3 \mathrm{MW}$ \\
\hline DC bus voltage & $1.5 \mathrm{kV}$ \\
\hline DC link capacitance & $100000 \mu \mathrm{F}$ \\
\hline
\end{tabular}

Table 2

Induction generator parameters

\begin{tabular}{|l|c|}
\hline \multicolumn{1}{|c|}{ Generator Type } & IGs \\
\hline MW & 7 \\
\hline Stator resistance & 0.01 \\
\hline
\end{tabular}




\begin{tabular}{|l|c|}
\hline Rotor resistance $(\mathrm{pu})$ & 0.01 \\
\hline Leakage reactance $(\mathrm{pu})$ & 0.1 \\
\hline Magnetizing reactance $(\mathrm{pu})$ & 3.5 \\
\hline Rotor mutual reactance $(\mathrm{pu})$ & 0.12 \\
\hline Inertia constant $(\mathrm{sec})$ & 1.5 \\
\hline Voltage rating, $\left(\mathrm{kV}_{\mathrm{LL}}\right)$ & 0.69 \\
\hline
\end{tabular}

\section{References}

[1] Aa N. D. Hatziargyriou and A. P. S. Meliopoulos, Distributed energy sources: Technical challenges, Proc. IEEE Power Eng. Soc. Winter Meeting, 2, New York, 2002, pp. 1017-1022.

[2] M. N. Ambia, A. Durra, S.M. Muyeen, Centralized Power Control Strategy for AC-DC Hybrid Microgrid System using Multi-converter Scheme, Proc. IECON 2011- 37th Annual Conference on IEEE Industrial Electronics Society, Melbourne, Australia, Nov. 7-10, 2011, pp. 843-848.

[3] M. N. Ambia, A. Durra, C. Caruana, and S.M. Muyeen, Islanding operation of hybrid micro-grid system with power management control scheme, 11th IASTED European conference on Power and Energy Systems (EURO PES 2012), Italy, Jun. 25-27. 2012.

[4] T. Senjyu, R. Sakamoto, N. Urasaki, T. Funabashi, H. Fujita and H. Sekine, Output power leveling of wind turbine generator for all operating regions by pitch angle control, IEEE Trans. Energy Convers., 21(2), pp. 467-475, Jun. 2006.

[5] S. Nomura, Y. Ohata, T. Hagita, H. Tsutsui, S. TsujiIio and R. Shimada, Wind farms linked by SMES systems, IEEE Trans. Appl. Supercond., 15(2), pp. 1951-1954, Jun. 2005.

[6] F. Zhou, G. Joos, C. Abbey, L. Jiao and B.T. Ooi, Use of large capacity SMES to improve the power quality and stability of wind farms, in Proc. IEEE Power Eng. Soc. Gen. Meeting, Jun. 2004, vol. 2, pp. 2025-2030.

[7] R. Takahashi, Wu. Li, T. Murata and J. Tamura, An application of flywheel energy storage system for wind energy conversion, Proc. Int. Conf. Power Electron. Drives Syst. (PEDS 2005), Nov., pp. 932937.

[8] R. Cardenas, R. Pena, G. Asher and J. Clare, Power smoothing in wind generations systems using a sensorless vector controlled induction machine driving a flywheel, IEEE Trans. Energy Convers., 19(1), pp. 206-216, Mar. 2004.

[9] R. L. Spyker and R. M. Nelms, Optimization of double-layer capacitor arrays, IEEE Trans. Ind. Appl., 36(1), pp. 194-198, Jan./Feb. 2000.

[10] T. Kinjo, T. Senjyu, N. Urasaki and H. Fujita, Output leveling of renewable energy by electric double-layer capacitor applied for energy storage system, IEEE Trans. Energy Convers. , 21(1), pp. 221-227, 2006.

[11] S. M. Muyeen, R. Takhashi, T. Murata and J. Tamura, Integration of an Energy Capacitor System
With a Variable-Speed Wind Generator, IEEE Trans. Energy Convers., 24(3), pp. 740-749, Sept. 2009.

[12] S.M. Muyeen, M.H. Ali, R. Takahashi, T. Murata, and J. Tamura, Wind generator output power smoothing and terminal voltage regulation by using STACOM/BESS, power Tech, 2007 IEEE Lausanne, pp. 1232-1237, Lausanne, 1-5 July 2007.

[13] S. M. Muyeen, J. Tamura, and T. Murata, Stability Augmentation of a Grid-connected Wind Farm, Springer-Verlag London, ISBN 978-1-84800-315-6, October 2008.

[14] M. Anderson, D. Carr, Battery energy storage technologies, Proceedings of the IEEE 81 (3) (1993) 475-479.

[15] W. Lachs, D. Sutanto, Application of battery energy storage in power systems, Proceedings of the International Conference on Power Electronics and Drive Systems, 2, February 21-24, 1995, pp. 700-705.

[16] N. Miller, R. Zrebic, R. Delmerico, G. Hunt, Battery energy storage systems for electric utility, industrial and commercial applications, Proceedings of the Eleventh Annual Battery Conference on Applications and Advances, January 9-12, 1996, pp. 235-240.

[17] I. Gyuk, P. Kulkarni, J.H. Sayer, J.D. Boyes, G.P. Corey, G.H. Peek, The united states of storage, IEEE Power and Energy Magazine 3 (2) (2005) 31-39.

[18] A. Joseph, M. Shahidehpour, Battery energy storage systems in electric power systems, IEEE (2006) 1-8.

[19] M. Kamibayashi, K. Tanaka, Recent sodium sulfur battery applications, in Transmission and Distribution Conference and Exposition IEEE/PES, 2001, vol. 2, pp. 1169-1173.

[20] M. Tsili, and S. Papathanassiou, A review of grid code technical requirements for wind farms, IET Renewable Power Generation, 3(3), pp. 308-332, 2009.

[21] F. Katiraei, M. R. Iravani and P. W. Lehn, Micro-grid Autonomous Operation During and Subsequent to Islanding Process, IEEE Trans. on Power Delivery, 20(1), pp. 248-257, January 2005.

[22] O. Wasynczuk etc, Dynamiac behavior of a class of wind turbine generators during random wind fluctuations, IEEE Trans. on Power Apparatus and Systems, PAS-100(6), pp.2854-2854, June 1981.

[23] Tomoki Asao, Rion Takahashi, Toshiaki Murata, Junji Tamura, et al, Smoothing Control of Wind Power Generator Output by Superconducting Magnetic Energy Storage System, Proceeding of International Conference on Electrical Machines and Systems 2007, Oct. 8-11, Seoul, Korea.

[24] K.E. Okedu, S.M. Muyeen, R. Takahashi, and J. Tamura, Comparative Study between Two Protection Schemes for DFIG-based Wind Generator, Proceedings of International Conference on Electrical Machines and Systems, pp. 62-67, Incheon, 10-13 Oct. 2010.

[25] PSCAD/EMTDC Manual, Manitoba HVDC Research Center, 1994. 